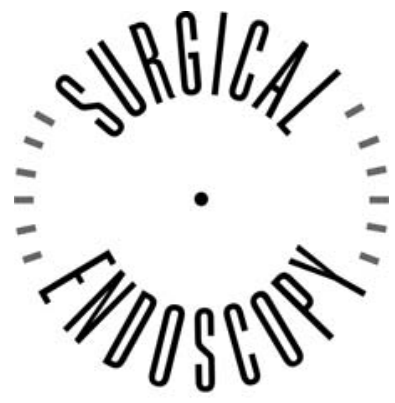

and Other Interventional Techniques

\title{
Colonoscopic perforations: a review of 30,366 patients
}

\author{
T. H. Lüning, ${ }^{1}$ M. E. Keemers-Gels, ${ }^{1}$ W. B. Barendregt, ${ }^{1}$ A. C. I. T. L. Tan, ${ }^{2}$ C. $\operatorname{Rosman}^{1}$ \\ ${ }^{1}$ Department of Surgery, Canisius-Wilhelmina Hospital, P.O. Box 9015, 6500 GS, Nijmegen, The Netherlands \\ ${ }^{2}$ Department of Gastroenterology, Canisius-Wilhelmina Hospital, P.O. Box 9015, 6500 GS, Nijmegen, The Netherlands
}

Received: 20 September 2006/Accepted: 25 November 2006/Online publication: 24 April 2007

\begin{abstract}
Background: Although the incidence of perforation after endoscopic procedures of the colon is low, the rising number of procedures could pose relevant health problems. Recognizing risk factors and optimizing treatment may reduce perforation incidence and the probability of (severe) complications. This study aimed to determine perforation frequency and the management of endoscopic colonoscopic perforation.

Methods: A retrospective review of patient records was performed for all patients with iatrogenic colonic perforations after sigmoido/colonoscopy between 1990 and 2005. The patients' demographic data, endoscopic procedural information, perforation location, therapy, and outcome were recorded.

Results: In the 16-year period, 30,366 endoscopic colonic procedures were performed. In total, 35 colonic perforations occured $(0.12 \%)$. All the patients underwent a laparotomy: for primary repair in 18 cases $(56 \%)$, for resection with anastomosis in 8 cases (25\%), and for resection without anastomosis in 6 cases (19\%). In three patients $(8.6 \%)$, no perforation was found. The postoperative course was uncomplicated in 21 cases $(60 \%)$ and complicated in 14 cases (40\%), including mortality for 3 patients (8.6\% resulting from perforations and $0.01 \%$ resulting from total endoscopic colon procedures). The relative risk ratio of colonoscopic and sigmoidoscopic procedures for perforations was 4 . Therapeutic procedures show a delay in presentation and diagnosis compared with diagnostic procedures. Of the 35 perforations, $26(74 \%)$ occurred in the sigmoid colon.

Conclusion: Iatrogenic colonic perforation is a serious but rare complication of colonoscopy. A perforation risk of $0.12 \%$ was found. The perforation risk was higher for colonoscopic procedures than for sigmoidoscopic procedures. The sigmoid colon is the area at greatest risk for perforation. Immediate operative
\end{abstract}

management, preferably primary repair and sometimes resection, appears to be a good strategy for most patients.

Key words: Colon perforation - Colonoscopy Complication - Endoscopy - Iatrogenic

Colonic perforation resulting from colonoscopic and sigmoidoscopic procedures is a rare but serious complication with high rates of morbidity and mortality [1, $3,6,7,12]$. The frequency of perforations after colonoscopy is estimated to be $0.03 \%$ to $0.8 \%$ for diagnostic colonoscopy and $0.15 \%$ to $3 \%$ for therapeutic colonoscopy [22]. With increasing numbers of colonoscopies being performed for screening purposes, this small possibility of perforations still may cause a high number of clinical problems. The optimal treatment for perforations, whether conservative or operative, still is unclear because no randomized trial has ever been conducted.

Recent studies are acquiring evidence for laparoscopic and endoluminal repair using clips for perforation closure [15-17, 19, 22]. Knowing risk factors, recognizing early signs of perforation, and giving early and optimal treatment may reduce the probability of (severe) complications and death from iatrogenic colon perforations. In this report, we review the literature and present the results of a 16-year retrospective analysis in a teaching hospital.

\section{Patients and methods}

Between 1990 and 2002, a record of all iatrogenic colonic perforations was kept. Perforations in 2003-2005 were found via the hospital information system using diagnosis (accidental perforation/laceration during diagnostic procedure) and procedure (colonic perforation) codes. A review investigated the records of all the patients with iatrogenic colonic perforations after sigmoido/colonoscopy from 1990 to 2005. The patients' demographic data, endoscopic information, clinical presentation, location, therapy, and outcome were recorded. 


\section{Results}

\section{Demographic}

Between 1990 and 2005, 30,366 endoscopic procedures of the colon $(9,209$ colonoscopic and 21,157 sigmoidoscopic procedures) were performed in our hospital. In this 16-year period, 35 patients were found to have iatrogenic perforation (incidence, $0.12 \%$ ). The perforations were divided unequally between the sexes, with 24 occurring in women and 11 in men. The percentage of women who had an endoscopic colonic procedure is not known, so the relative risk ratio cannot be calculated. The median age of the patients was 67 years (range, $42-$ 86 years).

\section{Indications and procedure type}

The indications for endoscopy in the patients with perforation were polyps $(n=17)$, anaemia/rectal bleeding $(n=8)$, diverticulosis/itis $(n=6)$, obstructive tumor $(n=3)$, and inflammatory bowel disease $(n=1)$. Perforation occurred 23 times during a colonoscopic procedure (incidence, $0.24 \%$ ) and 12 times during a sigmoidoscopic procedure (incidence, $0.06 \%$ ). The relative risk ratio of 4 showed that perforation is more likely with colonoscopic than with sigmoidoscopic procedures. A diagnostic procedure was performed for 12 of the perforation cases, and a therapeutic procedure was performed for 23 cases. The therapeutic procedures consisted of 15 polypectomies, 6 biopsies, and 2 laser treatments for angiodysplasia. Our hospital is a teaching hospital. All the procedures were performed by or under supervision of experienced endoscopists.

\section{Perforations}

In 13 cases (36\%), perforation was noticed by the endoscopist through visualization of extra-intestinal tissue during the procedure, and all but one patient underwent surgery on the same day. In five perforation cases, the remark, "difficult procedure," was made by the endoscopist in the report. Most perforations were diagnosed shortly after the procedure because of symptoms and signs of perforation. Altogether, 19 patients (54\%) underwent surgery on the same day as the endoscopy, 6 $(17 \%)$ on the second day, and $8(23 \%)$ more than 2 days after endoscopy. For two patients (5.7\%), the time between endoscopy and surgery could not be retrieved from the record. All perforations after diagnostic endoscopy were diagnosed and subjected to surgery the same day. This means that all perforations with a delayed presentation followed a therapeutic procedure.

Most perforations $(n=26,74 \%)$ occurred in the sigmoid colon, with $5(14 \%)$ occurring in the descending colon and 2 each $(6 \%)$ in the transverse colon and ascending colon. All 35 patients underwent surgery, although in one case, conservative treatment was started but a resection was performed 2 days later. In 3 of the 35 cases, serosal tears were seen with no actual perforation, and no oversewing was performed.
Three types of surgical correction were performed: primary repair, resection with anastomosis, and resection with colonic diversion. Primary repair was performed for 18 of the actual perforations (56\%), including one laparoscopic procedure. Resection with anastomosis was performed for eight patients (25\%), and a colonic diversion was performed for six patients (19\%). Because the absolute numbers of diagnostic and therapeutical procedures were not known, the perforation rates for the type of procedure could not be calculated.

\section{Complications}

Of the 35 patients, $21(60 \%)$ had no complications and showed a fast postoperative recovery. The remaining 14 patients $(40 \%)$ experienced complications: fascial dehiscence $(n=3)$, stenosis and anastomosis leakage (treated with relaparotomy) $(n=2)$, pulmonary embolism $(n=2)$, prolonged ileus $(n=1)$, allergic reaction to medication $(n=1)$, barium peritonitis after colon barium enema $(n=1)$ and cardio vascular accident (CVA) $(n=1)$. Three patients, all with serious comorbidity, died shortly after surgery. One patient died of a pulmonary cause, and twice it was decided to stop treatment for patients with high comorbidity of a cardiac and pulmonary origin. The 30-day hospital mortality rate was of $8.6 \%$. For all the patients with perforation, the mean hospital stay was 16 days (median, 13 days; range, 5-71 days).

\section{Discussion}

Perforation at the bowel wall, a serious complication of colonoscopy and sigmoidoscopy, often requires surgical intervention and has a high morbidity and mortality rate (Table 1). Findings have shown perforation risk to be $0.03 \%$ to $0.8 \%$ for diagnostic colonoscopy and $0.15 \%$ to $3 \%$ for therapeutic colonoscopy. These risk figures most likely are underreported because the studies depend on documentation accuracy $[1-5,7-10,13,22]$. It also is likely that some (smaller) perforations are missed completely, remaining subclinical and healing spontaneously. Subclinical perforations described as localized abdominal tenderness and short-lived pyrexia at presentation have proved to be "sealed perforations" at subsequent laparotomy for other reasons [14].

There is a difference in perforation risk between sigmoidoscopy and colonoscopy. This study found the perforation risk for colonoscopic procedures to be four times higher, exceeding the relative risk ratio of 2 described in previous reports [8]. Several studies have shown a difference in perforation rates between diagnostic and therapeutic procedures [4, 9].

Perforations follow three principal mechanisms: mechanical perforation by the endoscope's tip or loop (often in a difficult bend), barotraumas from overinsufflation (often in preexisting near perforations), and therapeutic procedures such as electrocoagulation for polypectomy and laser or argon plasma coagulation (rare). 
Table 1. Comparison of different articles

\begin{tabular}{|c|c|c|c|c|c|c|c|c|}
\hline Author (year) & Period & $\begin{array}{l}\text { No. of } \\
\text { patients }\end{array}$ & $\begin{array}{l}\text { No. of } \\
\text { perforations }\end{array}$ & $\begin{array}{l}\text { Perforation } \\
\text { incidence }\end{array}$ & $\begin{array}{l}\text { Mortality } \\
\text { incidence }\end{array}$ & $\begin{array}{l}\text { Mortality } \\
(\%)\end{array}$ & $\begin{array}{l}\text { Female } \\
(\%)\end{array}$ & $\begin{array}{l}\text { Surgery } \\
(\%)\end{array}$ \\
\hline Carpio et al. [3] (1989) & 1977-1987 & 5,424 & 14 & 0.260 & 0.050 & 19 & 57 & 58 \\
\hline Hall et al. [10] (1991) & $4-15$ year & 17,500 & 15 & 0.090 & 0.000 & 0 & 53 & 93 \\
\hline Gedebou et al. [9] (1996) & $1988-1993$ & 9,106 & 18 & 0.198 & 0.020 & 10 & 43 & 66 \\
\hline Farley et al. [5] (1997) & $1980-1995$ & 57,028 & 43 & 0.075 & 0.000 & 0 & 58 & 93 \\
\hline Anderson et al. [1] (2000) & $1987-1996$ & 10,486 & 20 & 0.191 & 0.019 & 10 & 64 & 100 \\
\hline Araghizadeh et al. [2] (2001) & 1970-1999 & 34,620 & 31 & 0.090 & 0.003 & 3 & 71 & 65 \\
\hline Gatto et al. [8] (2003) & 1991-1998 & 74,584 & 108 & 0.145 & 0.010 & 7 & 50 & \\
\hline Korman et al. [13] (2003) & 1999 & 116,000 & 37 & 0.032 & 0.000 & 0 & 73 & 95 \\
\hline Iqbal et al. [11] (2005) & 1994-2000 & 78,702 & 72 & 0.084 & 0.006 & 7 & 57 & 86 \\
\hline Current series & $1990-2005$ & 30,366 & 35 & 0.115 & 0.010 & 8.7 & 69 & 97 \\
\hline Total/average & & 433,816 & 393 & 0.091 & & & & \\
\hline
\end{tabular}

Perforations after therapeutic procedures often are diagnosed late, probably because of different pathophysiologic mechanisms [2, 4]. In diagnostic procedures, perforations most often result from pressure to the colonic wall and can be noticed immediately via visualization of extra-intestinal tissue by the endoscopist. In the case of therapeutic procedures, ischemia of the colonic wall caused by electrical or thermal injury after electrocoagulation or laser can cause delayed perforation. Our results showed an average of 0.36 days until perforation diagnosis after diagnostic procedures, as compared with 1.5 days after therapeutic procedures. Perforation risk is greatest for the sigmoid colon, presumably due to the bending of the sigmoid.

The current literature reports mortality rates of $0 \%$ to $50 \%$ [12]. The hospital mortality rate in the current study was $8.6 \%$. Most fatalities involved patients with serious comorbidities.

In three cases, no actual perforation was found during surgery. In one case, the endoscopist suspected a perforation during the procedure, and in two cases, perforation was suspected shortly after operation due to signs of peritonitis, fever, and leucocytosis. However, at surgery, only serosal tears were seen without a transmural perforation, and no free fluids or air was seen. Serosal tears without mucosal damage are a known complication of colonoscopy. Experiments proved that when a tip or bend of a colonoscope is pressed hard against the colonic mucosa, a serosal tear may occur, even when there is no mucosal perforation [20]. Another explanation maintains that no transmural perforation was found in the three cases because small perforations that did occur closed by themselves shortly thereafter without being noticed by the surgeon $[7,10]$.

Like most other studies, this study, showed more perforations among female patients (Table 1) [1-6, 10, $11,13,21]$. However, because the male-to-female ratio for all procedures is not known, the relative risk cannot be calculated. A statistical study showed similar risk for males and females [8]. One study showed a greater total colonic length in females, suggesting this as the cause for more difficult procedures [18].

Pelvic surgery, more commonly performed for females, is another risk factor for perforation mentioned in the literature [13]. Although more problems in the sigmoid colon of women would be expected because of pelvic surgery, we found comparable perforation percentages for the sigmoid colon between males and females.

Our survey showed that most patients with a perforation are treated surgically, and most authors agree that conservative treatment is advisable only if the perforation is diagnosed late and no peritoneal signs are present (Table 1). We started conservative treatment in only one patient, then changed to surgical treatment after 2 days because of unsatisfactory recovery $[3,5,10$, $11,21]$. Delaying surgery in some situations may lead to irretrievable situations [10].

A survey of published studies in 1991 showed a higher mortality rate for surgical treatment than for conservative treatment [10]. However, because this was only a descriptive study, we believe the two groups were not comparable, so no conclusions can be drawn from these results. It is very well possible that because the conservative group had fewer complaints, no immediate surgery was performed.

An alternative to both open operative repair and conservative treatment is a diagnostic laparoscopy. The perforation can be identified, and small perforations can be oversewn or small tangential resections can be performed. If difficult or complicated situations are identified, conversion to an open procedure can be performed. This study showed that 21 of the 35 perforations $(60 \%)$, were treated well with oversewing of the perforation $(n=18)$ or no surgery at all $(n=3)$. In these cases, laparoscopic treatment could have been a good alternative to an open procedure $[16,22]$.

Recent studies have shown the possibility of endoscopic perforation closure using endoclips. For small perforations, clipping can result in mucosal and submucosal healing, preventing fecal soiling of the peritoneal cavity. Clipping could be a helpful adjunct to conservative treatment, lowering the need for surgical intervention with its risks $[15,17,19]$.

\section{Conclusion}

Iatrogenic colonic perforation is a serious but rare complication of colonoscopy. Risks of perforation $(0.12 \%)$ and mortality $(0.01 \%)$ were found that are comparable with frequencies found in literature. Col- 
onoscopic procedures show a perforation risk four times higher than that for sigmoidoscopic procedures. Therapeutic procedures have a higher perforation risk than diagnostic procedures. The sigmoid colon is the area at greatest risk for perforation. Immediate operative management, preferably primary repair and sometimes resection, appears to be the best strategy for most patients. Conservative treatment is reserved for carefully selected patients only.

\section{References}

1. Anderson ML, Pasha TM, Leighton JA (2000) Enodoscopic perforation of the colon: lesson from a 10-year study. Am J Gastroenterol 95: 3418-3422

2. Araghizadeh FY, Timmcke AE, Opelka FG, Hicks TC, Beck DE (2001) Colonoscopic perforations. Dis Colon Rectum 44: 713-716

3. Carpio G, Albu E, Gumbs MA, Gerst PH (1989) Management of colonic perforation after colonoscopy: report of three cases. Dis Colon Rectum 32: 624-626

4. Dafnis G, Ekbom A, Pahlman L, Blomqvist P (2001) Complications of diagnostic and therapeutic colonoscopy within a defined population in Sweden. Gastrointest Endosc 54: 302-309

5. Farley DR, Bannon MP, Zietlow SP, Pemberton JH, Ilstrup DM, Larson DR (1997) Managment of colonoscopic perforations. Mayo Clin Proc 72: 729-733

6. Freitag M, Albert W, Petersen S, Ludwig K (2000) Die iatrogene colonperforation aus der sicht des chirurgen: erfahrung bei 11 patienten. Chirurg 71: 568-571

7. Garbay JR, Suc B, Rotman N, Fourtanier G, Escat J (1996) Multicentre study of surgical complications of colonoscopy. Br J Surg 83: 42-44

8. Gatto NM, Frucht H, Sundararajan V, Jacobson JS, Grann VR, Neugut AI (2003) Risk of perforation after colonoscopy and sigmoidoscopy: a population-based study. J Natl Cancer Inst 95: 230-236
9. Gedebou TM, Wong RA, Rappaport WD, Jaffe P, Kahsai D, Hunter GC (1996) Clinical presentation and management of iatrogenic colon perforations. Am J Surg 172: 454-458

10. Hall C, Dorricott NJ, Donovan IA, Neoptolemos JP (1991) Colon perforation during colonoscopy: surgical versus conservative management. Br J Surg 78: 542-544

11. Iqbal CW, Shin Chun Y, Farley DR (2005) Colonoscopic Perforations: a retrospective review. J Gastrointest Surg 9: 1229-1236

12. Jentchura D, Raute M, Winter J, Henkel T, Kraus M, Manegold BC (1994) Complications in endoscopy of the lower gastrointestinal tract: therapy and prognosis. Surg Endosc 8: 672-676

13. Korman LY, Overholt BF, Box T, Winker CK (2003) Perforation during colonoscopy in endoscopic ambulatory surgical centers. Gastrointest Endosc 58: 554-557

14. Macrae FA, Tan KG, Williams CB (1983) Towards safer colonoscopy: a report on the complications of 5,000 diagnostic and therapeutic colonoscopies. Gut 24: 376-383

15. Mana F, De Vogelaere K, Urban D (2001) Iatrogenic perforation of the colon during diagnostic colonoscopy: endoscopic treatment with clips. Gastrointest Endosc 54: 258-259

16. Miyahara M, Kitano S, Shimoda K, Bandoh T, Chikuba K, Maeo S, Kobayashi M (1996) Laparoscopic repair of a colonic perforation sustained during colonoscopy. Surg Endosc 10: 352-353

17. Raju GS, Pham B, Xiao S-Y, Brining D, Ahmed I (2005) A pilot study of endoscopic closure of colonic perforations with endoclips in a swine model. Gastrointest Endosc 62: 791-795

18. Saunders BP, Fukumoto M, Halligan S, Obling C, Moussa ME, Bartram CI, Williams CB (1996) Why is colonoscopy more difficult in women? Gastrointest-Endosc 43: 124-126

19. Taku K, Sano Y, Fu KI, Saito Y (2006) Iatrogenic perforation at therapeutic colonoscopy: should the endoscopist attempt closure using endoclips or transfer immediately to surgery? Endoscopy 38: 428

20. Uno Y, Morita T (1997) Colonic perforation and serosal tears associated with colonoscopy. Lancet 349: 1888

21. Vincent M, Smith LE (1983) Management of perforation due to colonoscopy. Dis Colon Rectum 26: 61-63

22. Wullstein Ch, Köppen MO, Gross E (1999) Laparoscopic treatment of colonic perforations related to colonoscopy. Surg Endosc 13: $484-487$ 